Spatial Demography 2014 2(1): 55-65

http://spatialdemography.org

OPEN ACCESS

via Creative Commons 3.0
ISSN 2164-7070 (online)

\title{
RESEARCH
}

\section{Validating Adolescent Socioeconomic Status: Comparing School Free or Reduced Price Lunch with Community Measures}

\author{
Lisa M. Nicholson ${ }^{1}$, Sandy J. Slater ${ }^{1}$, Jamie F. Chriqui ${ }^{1}$, and Frank Chaloupka ${ }^{1}$ \\ ${ }^{1}$ The Institute for Health Research and Policy Health Policy Center \\ University of Illinois Chicago, USA
}

\begin{abstract}
The use of free or reduced price lunch (FRL), as a measure of socioeconomic status (SES), has received mixed reviews in the literature. This study expands on the limited research on the validity of FRL as a measure of SES by examining the relationship between FRL and a series of communitybased SES measures to determine whether FRL is an adequate proxy for adolescent SES. Data are from a nationally representative sample of 154 public high schools in 2010 from Bridging the Gap with corresponding school level data from the National Center for Education Statistics' (NCES) Common Core of Data (CCD) to obtain a measure of percent of students receiving FRL and using ArcGIS 9 software with the ACS 05-09, matched at the census block group level to construct measures of community SES. School zone level SES measures obtained include: median household income, percent of families in poverty, percent of families with children younger than 18 years in poverty, and the percent of all households in poverty. Data collected through community observations were used to construct a physical disorder scale. Percent FRL was strongly and significantly associated with the percent of families in poverty $(\mathrm{r}=0.67)$, percent of families with children younger than 18 years $(\mathrm{r}=0.67)$, percent of households in poverty $(\mathrm{r}=0.66)$, median household income $(\mathrm{r}=-0.60)$, and physical disorder $(\mathrm{r}=0.56)$ in the expected directions. Additionally, all community based measures of socioeconomic status were highly correlated with each other. The validity and limitations of FRL as a proxy for adolescent SES are discussed.
\end{abstract}

KEYWORDS: health, child health, health policy, community health, school health

\section{INTRODUCTION}

Research has demonstrated that socioeconomic status (SES) is an important determinant of many youth behaviors and related health outcomes (Goodman, Slap, and Huang 2003), but measuring SES for youth remains challenging. Despite decades of research, the way to measure socioeconomic status among youth remains contested. In addition to traditionally used individual level measures of parental income and mother's education (Entwisle and Astone 1994; Hauser 1994) and family based measures of household composition, family income, educational attainment, and education status (Hernandez 1997), researchers today have more access to measures of socioeconomic context

Corresponding Author: Lisa M. Nicholson, PhD, Visiting Research Scientist, University of Illinois Chicago, 1747 W.

Roosevelt Road, Chicago, IL 60608

Email: $\underline{\text { lnicho4@uic.edu }}$ 
including measures of the school and neighborhood environment. Mounting research evidence indicates that the socioeconomic characteristics of neighborhoods can influence health, over and above individual level SES (Robert 1999; Yen and Syme 1999; Pickett and Pearl 2001; Sampson, Morenoff, and GannonRowley 2002) and these effects may be especially strong for youth during the transition to adulthood (Nicholson and Browning 2012). Still other educational and health research, without access to geocoded data and neighborhood context, use the school level measure of free or reduced price lunch (FRL) as a measure of SES (Nierman and Veak 1997; Kurki, Boyle, and Aladjem 2005). A very limited body of research has examined the validity of FRL as a measure of youth SES (Ensminger et al. 2000), although the measure is frequently used in education and health research (Harwell and LeBeau 2010). Of all the measures of SES, FRL has received the least attention and remains highly criticized.

The increased use of FRL as a proxy for SES for adolescents, schools, and school districts, and the use of FRL as a school-based health intervention mechanism, emphasizes the need for the validation of this measure compared to other measures of community SES. FRL remains highly criticized in part, because one of the criteria to receive FRL is based on the U.S. poverty index, a measure that is often argued by researchers as being outdated (Kurki et al. 2005; Harwell and LeBeau 2010). Increasing evidence of the importance of neighborhood effects combined with the mixed results of associations with FRL and proximal health outcomes, suggests the need to examine the validity of FRL as a measure of SES, specifically compared to other community based measures. Our study is the first we know of to examine the associations of FRL with other community based measures of SES. Our study will build on previous research validating FRL with individual level measures of SES from adolescents and parent reports (Ensminger et al. 2000), by examining the associations of FRL with community based SES measures. This will advance the field by testing the criticism that FRL does not adequately capture current SES, by incorporating measures of neighborhood context.

\section{BACKGROUND}

\section{Individual Measures of Adolescent SES}

A review of the literature indicates that a variety of individual level variables have served as a measure of youth SES, both independently and in combination to form a scale, however there is virtually no standardization. The most frequently used measure is mother's education (Ensminger and Fothergill 2003), likely because it is not refused as frequently in surveys as income questions (Duncan and Magnuson 2003). Other commonly used single measures include parental income (Worly and Story 1967), parental occupation (Miner 1968), and student mobility (Herr and Tobias 1970). Family poverty and affluence are sometimes used but researchers somewhat agree that the measures are too volatile for use (Duncan and Magnuson 2003). Longstanding research has revealed high correlations among measures of parental education, income, and occupation leading many researchers to argue that the variables could not be used in combination in models. However, more recent research argues that income and education are not interchangeable and, although the measures are highly correlated, these correlations are generally not strong enough to justify using one as a proxy for the other (Braveman et al. 2005).

The argument for the use of multiple individual level measures or scaled measures (Hollingshead 1975) has been long argued by other researchers. Entwisle and Astone (1994) argued for the use of income, mothers' education, and household and family structure. Ensmigner et al. (2000) argued for the use of mothers' education in combination with adolescents' self-reported items as a way to overcome the limited information that adolescents usually report. Hauser (1994) suggested focusing on the major adult earner in the household and to ascertain their education, labor force status, and occupational position. Hernandez (1997) discussed the use of census based measures of household composition, family 
income, educational attainment, race and ethnicity, and employment, but few research databases allow for such geocoded matches today. Very little research has examined the Hollingshead Four-Factor Index of Social Status with other measures of SES or with health or behavioral outcomes, although the scale was designed for use in adolescents (Ensminger and Fothergill 2003) and it has been argued that SES is too multifaceted to be captured by a single index like this one (Duncan and Magnuson 2003). Studies suggest that although the best measure of SES for a given study depends on the research question of that study, including multiple measures of SES may be best for capturing all dimensions of adolescent SES (Entwisle and Astone 1994). Therefore, there is some consensus that multiple components should be measured and used separately in the models (Krieger, Williams, and Moss 1997; Duncan and Magnuson 2003).

\section{Neighborhood Context as a Measure of SES}

Advances in statistical methodology, specifically multilevel modeling, has allowed for the incorporation of neighborhood effects into many fields of research. Youth neighborhood socioeconomic context has been shown to correlate with proximal health outcomes, such as physical activity settings as well as adolescent health outcomes including obesity (GordonLarsen et al. 2006) and the effects may be particularly critical to youth during the transition to adulthood (Nicholson and Browning 2012). Most importantly, studies find that neighborhood conditions, particularly SES, are accounted for, in part, by family SES, yet also have somewhat small (5-10\% of variance) but independent effects on youth outcomes (Leventhal and Brooks-Gunn 2003). It is likely that neighborhood SES effects, especially those involving youth, operate through mechanisms such as families, peers, and schools (Elliott et al. 1996; Klevanov, Brooks-Gunn, Chase-Lansdale, and Gordon 1997; Sampson 1997). It is very important for neighborhood SES studies to point to specific underlying mechanisms at work in order for necessary policy recommendations to be made (Leventhal and Brooks-Gunn 2003). These underlying mechanisms require a great amount of research since they likely vary by both the outcome of interest and the age of the target population, with variations across children, adolescents, and young adults (Leventhal and Brooks-Gunn 2003).

Measuring neighborhood SES, often referred to as neighborhood disadvantage or advantage has no consistent measurement in the field, although the measure is usually scaled, as opposed to including a series of measures. Neighborhood context literature is currently dominated by poverty and demographic characteristics drawn from census data, which may or may not actually reflect the true characteristics of neighborhoods (Raudenbush 2003). One somewhat frequently used measure of adolescent neighborhood disadvantage is measured using a summed standardized scale from previous research (see Haynie et al. 2006; Nicholson and Browning 2012). The scale comprises four items (alpha $=0$. 93) at the census tract level: the proportion receiving public assistance, the proportion of female-headed families with children younger than 18 years of age and no husband present, the proportion of people living below the poverty level, and the total unemployment rate. However, it is important to note that although commonly used neighborhood context scales have been tested and show strong indications of validity in measurement, social context literature is decades behind the psychometric literature validating individual-level measures of SES that have excellent statistical properties (Raudenbush 2003).

\section{School FRL as a Measure of SES}

In the United States, students who meet federal United States Department of Agriculture (USDA) guidelines are eligible for free or reduced price lunch

(http://www.fns.usda.gov/cnd/application/Fami lyFriendly/english.pdf). The most commonly cited eligibility guideline is that students from families with incomes at or below $130 \%$ of the poverty level are eligible for free lunch and those between $130 \%$ and $185 \%$ are eligible for a reduced-price lunch. However, all children in households receiving benefits from the 
Supplemental Nutrition Assistance Program (SNAP), the Food Distribution Program on Indian Reservations, or, in some states Temporary Assistance for Needy Families (TANF), can get free meals regardless of income. Additionally, any foster, homeless, runaway, or migrant child can get free meals regardless of household income. Children in households receiving assistance from the Women Infants and Children Program (WIC) may also be automatically eligible for free lunches. The assumption in research is that students eligible for free or reduced price lunch have lower SES than those from non-eligible households, but the guidelines may allow for instances where misclassifications can occur.

Although FRL is widely used in education and health research as a measure of SES, it has received continued criticism (Entwisle and Astone 1994; Hauser 1994; Kurkie, Boyle, and Aladjem 2005) and results of the association of FRL with proximal health outcomes, such as the school food environment, have found mixed results. A recent study by Taber and colleagues (2013) finds that in states that exceeded USDA school meal standards, the difference in obesity prevalence between students who obtained free or reduced price lunches and those who did not was significantly lower than in states that did not exceed USDA standards. Other studies have found negative or null findings when examining the association between FRL and the school food environment (Briefel et al. 2009; Finkelstein, Hill, and Whitaker 2008). Mixed associations with FRL with health outcomes and proximal outcomes have led some to conclude that the FRL is based on the outdated poverty index (Hauser) and does not adequately capture all economic elements that are relevant today, such as the effects of concentrated neighborhood poverty (Kurki et al. 2005) or students access to economic resources (Harwell and LeBeau 2010). In sum, there is very little consensus in the field as to the usefulness of FRL as a current measure of youth SES.

A very limited body of research has examined the validity of FRL as a measure of youth SES (Ensminger et al. 2000), and our study is the first we know of to examine the associations of FRL with other community based measures of SES. One study has established that adolescent selfreported measures of SES were linked to mother's report of income and that the SES measures related in the expected direction to adolescent self-reported health outcomes, with higher SES adolescents more likely to report better physical and emotional health (Ensminger et al. 2000). Our study will build on previous research validating FRL with individual level measures of SES from adolescent and parent reports, by examining the associations of FRL with community based SES measures. This will advance the field by testing the criticism that FRL does not adequately capture current SES, by incorporating measures of neighborhood context.

\section{METHODS}

This study combined cross-sectional data collected in spring 2010 from a nationally representative sample of 154 public high schools participating in the Monitoring the Future (MTF) survey (see Johnston et al. 2011 for more information) with corresponding school level data from the National Center for Education Statistics' (NCES) Common Core of Data (CCD) and community SES measures from the American Community Survey (ACS) 2005-2009 and onthe-ground observational data collection. Only the traditional public schools involved in Year 2 of MTF participation were included in this study ( $\mathrm{N}=154 \quad$ schools). Community level environmental measures for the MTF school enrollment zones, the area from which schools draw their student population (area, in square miles: median size $=39.8$, range $=0.26-1517$, were developed through the Community Obesity Measures Project (BTG-COMP), an ongoing, large-scale effort conducted by the Bridging the Gap Research team. BTG-COMP identifies local policy and environmental factors that are likely to be important determinants of healthy eating, physical activity, and obesity among children and adolescents. This study was approved by the Institutional Review Board at the University of Illinois Chicago. 
Figure 1. Overlay of block groups selected from within the school enrollment zone

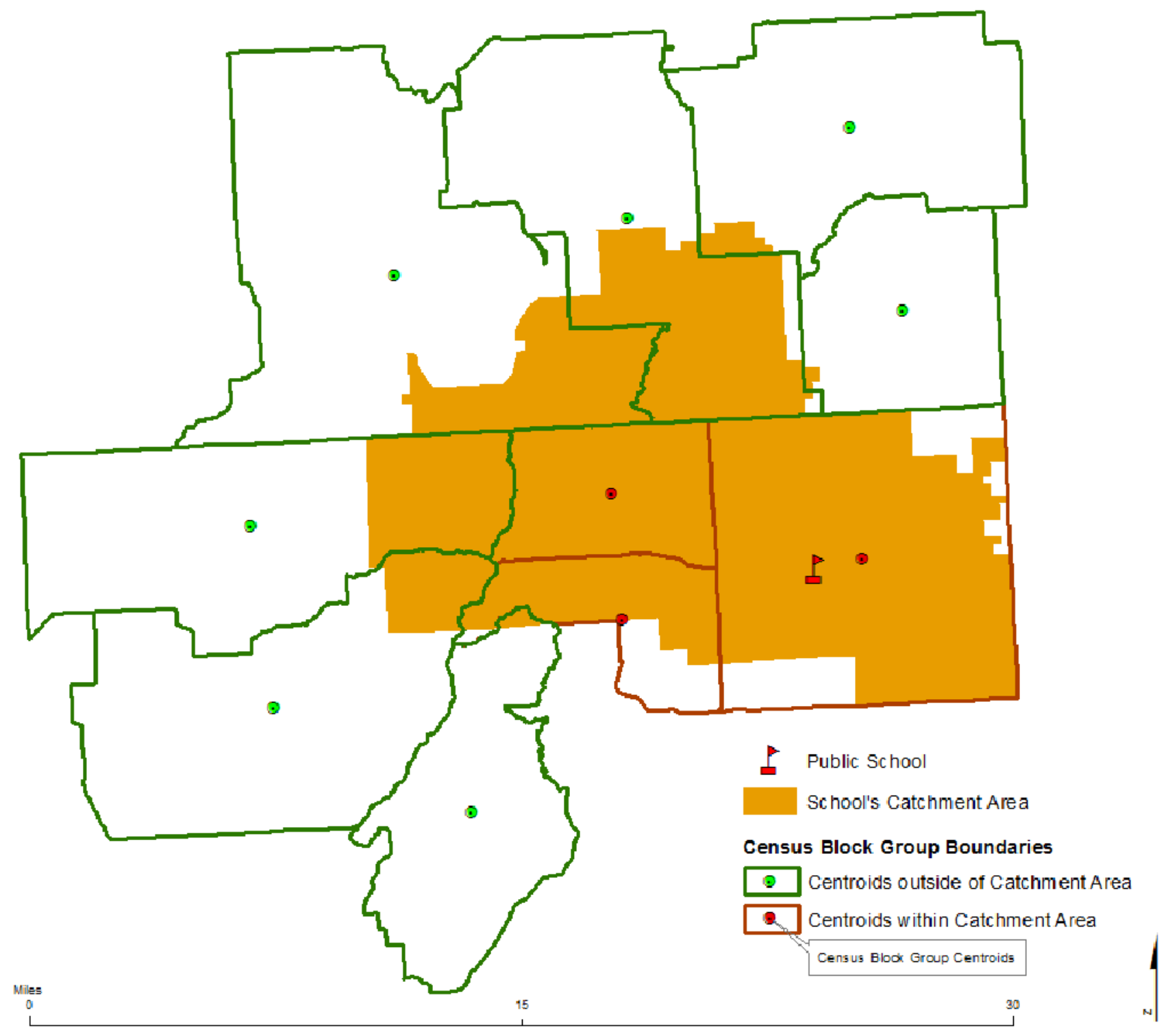

\section{Community Measures}

Using ArcGIS 9 software with the ACS 05-09, matched at the census block group level to the school enrolment zone described above we constructed measures of community SES. Figure 1 shows that block groups with centroids within the school enrollment zone were included in the analysis, while other block groups with partial overlap or adjacent borders were excluded. Socioeconomic measures obtained included: median household income, percent of families in poverty, percent of families with children younger than 18 years in poverty, and percent of all households in poverty. Median household income was calculated for the school enrollment zone as the average median household income across the block groups selected. All other socioeconomic measures were computed by calculating the total number of individuals in each poverty category, divided by the total number of individuals living in all selected block groups, and multiplying by 100. Other techniques using intersecting block groups with the school 
enrollment zone boundary were also tested and yielded virtually identical results.

Data collected through community observations via on-the-ground field work were used to construct a physical disorder scale including measures on the presence or absence of: (1) homeless persons loitering on the streets; (2) bars on windows of buildings; (3) unkempt or dilapidated buildings; (4) security barriers around residential and retail property; (5) teens hanging out (showing negative behaviors such as smoking or drinking); and (6) vandalism and/or graffiti (Cronbach's alpha $=0.75$ ). The measure is the proportion of streets in the catchment area with physical disorder present. A more detailed description of the street audit tool is described elsewhere (Slater et al. 2013).

\section{School Level Measures}

School level demographic and socioeconomic data were obtained from the National Center for Education Statistics' Common Core of Data (NCES 2011). Data were obtained from the 200809 school year data (2009-10 data were not available at the time of analysis). Data were obtained on the percentage of students eligible for FRL, region, and locale. The percent of FRL is calculated as the number of students receiving FRL divided by the total number of students in a given school, multiplied by 100 .

\section{Data Analysis}

All data were analyzed using STATA SE v. 12 and all results indicate the p-value level of significance. No results were considered statistically significant unless $\mathrm{p}<.05$. Descriptive statistics were calculated for all variables (Table 1).

After removing cases with missing data on the percentage of students eligible for a free or reduced price lunch $(\mathrm{N}=14), 140$ public high schools remained for analysis. Pearson regression coefficients were first compared to examine the strength of associations among variables. Next, multivariate ordinary least square regressions were conducted to examine associations with key variables of region and locale. Regression based power analysis determined that the sample size was large enough to determine statistical significance at 90\% power including five control variables in the models. Schools were somewhat evenly distributed across regions (West $\mathrm{n}=26,19 \%$; Midwest $\mathrm{n}=39,28 \%$; South $n=43,31 \%$; Northeast $n=32,23 \%)$ and locale (urban $n=28,20 \%$; suburban $n=49,35 \%$, rural $n=63,45 \%)$. Lastly, principal component analysis (PCA) and Stata's biplot for PCA (Kohler and Luniak 2005) were completed to examine the extent to which common variance was appreciably shared between FRL and the other indicators of SES.

\section{RESULTS}

Table 1 displays descriptive characteristics and pearson's correlation coefficients for all socioeconomic variables. Percent FRL was strongly and significantly associated with the percent of families in poverty $(\mathrm{r}=0.67)$, percent of families with children younger than 18 years $(\mathrm{r}=0.67)$, percent of households in poverty $(\mathrm{r}=0.66)$, median household income $(\mathrm{r}=-0.60)$, and physical disorder $(\mathrm{r}=0.56)$ in the expected directions. Additionally, all community based measures of socioeconomic status were highly correlated with each other.

Results from Table 2 display additional examination of potential differences in associations of locale and region with all socioeconomic variables. As expected from the correlation results described above, percent FRL tracks similarly with percent of families in poverty, percent of families with children younger than 18 years in poverty, and the physical disorder scale, and in the opposite direction as median household income. Results of associations with predictors are more consistent for urban versus suburban, and Midwest or South versus Northeast.

Figure 2 plots the results of the PCA biplot analysis. In a biplot, the length of the lines approximates the varianaces of the variables with longer lines indicating higher variance. Based on 
Table 1. Descriptive statistics and correlations ( $N=140$ schools for all variables)

\begin{tabular}{lllllllll}
\hline \multicolumn{1}{c}{ Variable } & Mean(SD) & Range & $\mathbf{1}$ & $\mathbf{2}$ & $\mathbf{3}$ & $\mathbf{4}$ & $\mathbf{5}$ & $\mathbf{6}$ \\
\hline 1. \% Free-reduced lunch & $40.9(24.9)$ & $0.0-99.8$ & 1.00 & & & & & \\
2. \% families in poverty & $10.0(7.3)$ & $0.6-57.8$ & 0.67 & 1.00 & & & & \\
$\begin{array}{l}\text { 3. \% families with children }<18 \text { in } \\
\text { poverty }\end{array}$ & $15.6(12.8)$ & $0.2-100.0$ & 0.67 & 0.98 & 1.00 & & & \\
$\begin{array}{l}\text { 4. \% of households in poverty } \\
\text { 5. Median household income }\end{array}$ & $12.4(7.5)$ & $2.1-53.7$ & 0.66 & 0.95 & 0.80 & 1.00 & & \\
& 54795.6 & $13175.7-$ & -0.60 & -0.62 & -0.57 & -0.67 & 1.00 \\
$\begin{array}{l}\text { 6. Prop of streets with physical } \\
\text { disorder }\end{array}$ & $0.4(0.3)$ & $0.0-1.0$ & 0.56 & 0.53 & 0.67 & 0.49 & -0.32 & 1.00 \\
\hline
\end{tabular}

Notes: all correlations are significant at $\mathrm{p}<.001$ (2-tailed)

Table 2. Results of linear regression analysis predicting SES variables ( $\mathrm{N}=140)$

\begin{tabular}{lcccccc}
\hline & $\begin{array}{c}\text { \% Free- } \\
\text { reduced lunch }\end{array}$ & $\begin{array}{c}\text { \% families in } \\
\text { poverty }\end{array}$ & $\begin{array}{c}\text { \% of } \\
\text { households } \\
\text { in poverty }\end{array}$ & $\begin{array}{c}\text { Median } \\
\text { household } \\
\text { income }\end{array}$ & $\begin{array}{c}\text { \% } \\
\text { households } \\
\text { in poverty }\end{array}$ & $\begin{array}{c}\text { Physical } \\
\text { disorder } \\
\text { scale }\end{array}$ \\
\hline Suburban & $\underline{\mathrm{b}(\mathrm{s} . \mathrm{e} .)}$ & $\underline{\mathrm{b}(\mathrm{s} . \mathrm{e} .)}$ & $\underline{\mathrm{b}(\mathrm{s} . \mathrm{e} .)}$ & $\underline{\mathrm{b}(\mathrm{s} . \mathrm{e} .)}$ & $\underline{\mathrm{b}(\mathrm{s} . \mathrm{e} .)}$ & $\underline{\mathrm{b}(\mathrm{s} . \mathrm{e} .)}$ \\
Rural & $-0.1(\mathrm{o}) \mathrm{n})^{* *}$ & $-4.5(1.4)^{* *}$ & $-7.5(2.4)^{* *}$ & $9760.3(4016.2)^{*}$ & $-4.8(1.4)^{* *}$ & $-1.1(0.2)^{* *}$ \\
West & $-1.8(1.4)$ & $-5.0(2.4)^{*}$ & $-7457.9(4104.0)$ & $-0.9(1.4)$ & $-1.4(0.1)^{* *}$ \\
Midwest & $-0.1(0.1)^{*}$ & $3.1(1.6)$ & $6.5(2.8)^{*}$ & $-3113.9(4792.9)$ & $2.1(1.7)$ & $0.4(0.2)$ \\
South & $0.1(0.1)^{* *}$ & $-2.5(1.6)$ & $-4.3(2.8)$ & $1719.8(4659.6)$ & $-3.1(1.6)$ & $-0.3(0.2)$ \\
\hline
\end{tabular}

Notes: Urban is the omitted category for locale and northeast is the omitted category for region. ${ }^{*} \mathrm{p}<.05$ (2tailed); ${ }^{* *} \mathrm{p}<.01$ (2-tailed)

Figure 2, results suggest that all variables are of similar variance with slightly less variance in the percentage of families in poverty and physical disorder. The cosine of the angles between the lines indicates correlation. Angles of o or 180 degrees reflect strong correlations of 1 while 90 and 270 degrees suggest smaller correlations. Again, all variables have similar angles of 30 to 45 degrees, suggesting strong and consistent correlation.

\section{DISCUSSION}

The purpose of this study was to conduct an exploratory analysis of associations among frequently used measures of adolescent SES. We were especially interested in the potential correlation between the school based measure of percent of FRL with community based measures including: percent of families in poverty, percent of families with children younger than 18 years in poverty, percent of households in poverty, median household income, and neighborhood physical disorder. We found strong associations among all SES measures. These associations remained consistent for urban and suburban areas as well as for Northeast, Midwest, and Southern regions in our sample. Caution should still be taken when deciding on the most appropriate measure of SES for rural locales and the West region. We also noted that this study only validated the school-based measure of FRL and does not assess the measure of FRL 
Figure 2. Biplot for principal component analysis

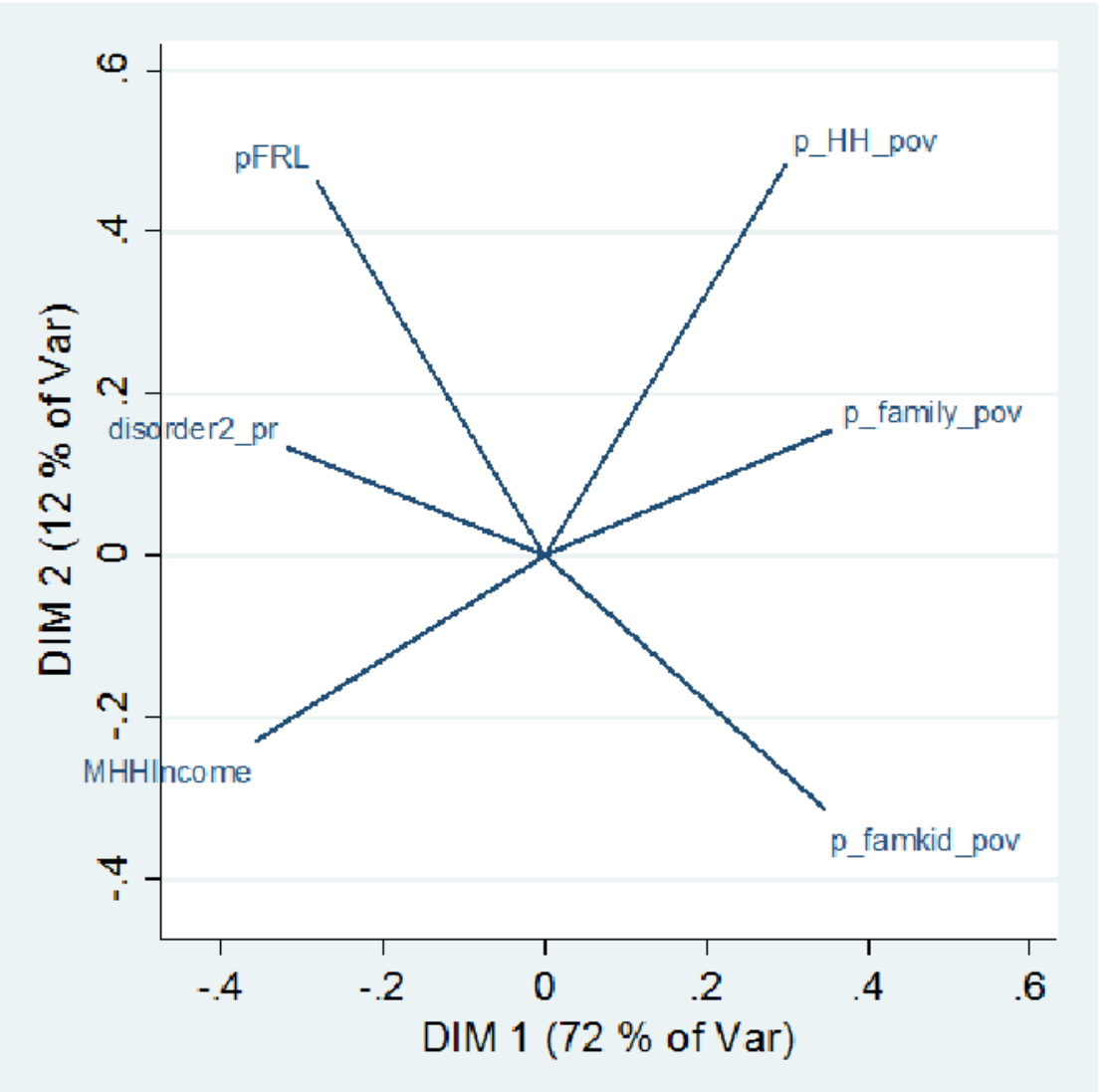

aggregated at the school district level.

The measure of FRL suffers from many of the same limitations as other community based measures. For instance, FRL, much like neighborhood disadvantage, suffers from the possibility of differential selection. In the example of FRL, poorer, less healthy students may select into poorer schools with lower quality meals and a lack of resources, making it difficult to disentangle the true effect of FRL compared to the prior poverty of selection. Also important to note is that youth are nested in many environments simultaneously including peer groups, schools, neighborhoods, families, workplaces, and religious institutions, and these environments may have mediating and/moderating effects with each other in association with any outcome.

Based on the data presented herein, FRL does appear to be an adequate proxy for adolescent SES in school based studies. This finding came as somewhat of a surprise given the fact that existing school-based studies have not found FRL to be significantly associated with school or student based outcomes (Finkelstein, Hill, and Whitaker 2008; Briefel et al. 2009). One explanation could be that FRL (or SES) is not driving school policies/practices related to school food and/or physical activity environments. Instead, other factors such as state and/or district requirements, geography, and urban/rural distinctions may be more important than measures of SES (Taber, Chriqui, and Chaloupka 2011). Another possibility for the null findings could relate to policy implementation. In one case study, researchers found that low SES school districts that had strong competitive food policies did not have as many barriers to implementation, because fewer students could afford to purchase competitive foods and were already on FRL. 
Thus, policy implementation was stronger in low SES (high FRL) districts, possibly offsetting lower levels of implementation/compliance in higher SES districts, leading to null findings (Bassler et al. 2013). Thus, this area of research will continue to require further exploration and should be expanded to examine correlations between district FRL and community SES.

\section{Competing Interest}

Competing Interest: None to declare.

\section{Funding Statement}

This work was supported by The Robert Wood Johnson Foundation (RWJF) grant number 64702.

\section{Contributorship Statement}

All authors fulfill the ICMJE criteria for authorship, and there is no one else who fulfill the criteria who has not been included as an author. LMN has contributed to conception, design, analysis, interpretation of the data, and drafted the manuscript. JFC has contributed to conception and design, interpretation of the data, and revisions of the drafted manuscript. SJS has contributed to conception and design, analysis, interpretation of the data, data acquisition, and revisions of the drafted manuscript. FJC has contributed to conception and design, interpretation of the data, data acquisition, funding, and revisions of the drafted manuscript.

\section{References}

Bassler EJ, Chriqui JF, Stagg K, Schneider LM, Infusino K, Asada Y. 2013. Controlling Junk Food and the Bottom Line: Case Studies of Schools Successfully Implementing Strong Nutrition Standards for Competitive Foods and Beverages. Chicago, IL: Illinois Public
Health Institute. Available:

http://iphionline.org/2013/o3/controlling-junk-food/

Boyce W, Toresheim T, Currie C, et al. The family affluence scale as a measure of national wealth: validation of an adolescent self-report measure. Social Indicators Research 2006;78:473-87.

Braveman P, Cubbin C, Egerter S, et al. Socioeconomic status in health research one size does not fit all. JAMA 2005;294:2879-2888.

Briefel RR, Crepinsek MK, Cabili C, et al. School food environment and practices affect dietary behaviors of US public school children. JADA 2009;109:S91-S107.

Brooks-Gunn J, Duncan GJ, Aber JL. Neighborhood Poverty: Context and Consequences for Children: Vol. 1. New York: Russell Sage Foundation Press, 1997.

Caldas SJ, Bankston C. Effect of school population socioeconomic status on individual academic achievement. $J$ Educ Res 1997;90:269-277.

Duncan GJ, Magnuson KA. Off with Hollinsghead: Socioeconomic resources, parenting, and child development, 2003; In Socioeconomic Status, Parenting, and Child Development edited by Marc H. Bornstein and Robert H. Bradle, pages 83-106. Mahwah: New Jersey.

Elliott D, Wilson WJ, Huizinga D, et al. The effects of neighborhood disadvantage on adolescent development. Journal of Research in Crime and Delinquency 1996; 33:389-426.

Ensminger ME, Fothergill K. A decade of measuring SES: What it tells us and where to go from here, 2003; In Socioeconomic Status, Parenting, and Child Development edited by Marc H. Bornstein and Robert H. Bradley, pages 13-28. Mahwah: New Jersey.

Ensminger ME, Forrest CB, Riley AW, et al. The validity of measures of socioeconomic status of adolescents. $J$ Adolesc Res 2000;15:392-419.

Entwisle DR, Astone NM. Some practical guidelines for measuring youth's race/ethnicity and socioeconomic status. Child Development 1994;65:1521-1540.

Finkelstein DM, Hill EL, Whitaker RC. School food environments and policies in US public schools. Pediatrics 2008; 122:e251-59. 
Goodman E, Slap GB, Huang B. The public health impact of socioeconomic status on adolescent depression and obesity. AJPH 2003;93:1844-50.

Gordon-Larsen P, Nelson MC, Page P, et al. Inequality in the built environment underlies key health disparities in physical activity and obesity. Pediatrics 2006;117:417-24.

Harwell M, LeBeau B. Student eligibility for a free lunch as an SES measure in education research. Educational Researcher 2010; 39:120-131.

Hauser RM. Measuring socioeconomic status in studies of child development. Child Development 1994; 65:1541-1545.

Haynie DL, Silver E, Teasdale B. Neighborhood characteristics, peer influence, and adolescent violence. Journal of Quantitative Criminology 2006; 22:147-169.

Hernandez DJ. Child development and the social demography of childhood. Child Development 1997; 68:149-169.

Herr A, Tobias S. Achievement via programmed instruction and socioeconomic status. Psychology in the Schools 1970; 1:53-56.

Hollingshead, AA. Four-factor index of social status. 1975; Unpublished manuscript, Yale University, New Haven, CT.

Johnston LD, O’Malley PM, Bachman JG, Schulenberg J. Monitoring the Future national survey results on drug use, secondary school students, volume I. 19752010. Ann Arbor: Institute for Social Research, University of Michigan, 2011.

www.bridgingthegapresearch.org.

Klevanov PK, Brooks-Gunn J, Chase-Lansdale PL, Gordon R. 1997. Are neighborhood effects on young children mediated by features of the home environment? In J. Brooks-Gunn, GJ Duncan, and JL Abers (Eds.), Neighborhood poverty: Contest and consequences for children (Vol I); (pp 119-145). New York: Russell Sage.

Kohler U, Luniak M. Data inspection using biplots. The Stata Journal 2005; 5:208-223.

Krieger N, Williams DR, Moss NE. Measuring social class in US public health research: concepts, methodologies and guidelines. Annual Review of Public Health 1997; 18:341-378.

Kurki A, Boyle A, Aladjem DK. (2005, April). Beyond free lunch: Alternative poverty measures in educational research and program evaluation. Paper presented at the annual meeting of the American Educational Research Association, Montreal, Canada.

Leventhal T, Brooks-Gunn J. Moving on up: Neighborhood effects on children and families, 2003; In Socioeconomic Status, Parenting, and Child Development edited by Marc H. Bornstein and Robert H. Bradley, pages 209-30. Mahwah: New Jersey.

Miner B. Sociological background variables affecting school achievement. Journal of Educational Research 1968; 61:372-381.

National Center for Education Statistics (NCES). U.S. Department of Education. Institute of Education Sciences, National Center for Education Statistics, 2006-2007. Available at:

http://nces.ed.gov/ccd/pubschuniv.asp. Accessed January 10, 2011.

Nicholson LM, Browning CR. Racial and ethnic disparities in obesity during the transition to adulthood: The contingent and nonlinear impact of neighborhood disadvantage. Journal of Youth and Adolescence 2012; 41:53-66.

Nierman GE, Veak MH. Effect on selected recruiting strategies on beginning instrumentalists' participation decisions. Journal of Research in Music Education 1997; 45:380-389.

Pickett KE, Pearl M. Multilevel analyses of neighborhood socioeconomic context and health outcomes: a critical review. Journal of Epidemiology and Community Health 2001; 55:111-122.

Raudenbush S. The quantitative assessment of neighborhood social environments. 2003. In Kawachi I and Berkman L, edts: Neighborhoods and Health. New York: Oxford University Press.

Robert SA. Socioeconomic position and health: the independent contribution of community socioeconomic context. Annual Review of Sociology 1999; 25:489-516.

Sampson RJ, Morenoff JD, Gannon-Rowley T. Assessing "neighborhood effects": social processes and 
new directions in research. Annual Review of Sociology 2002; 28:443-478.

Sampson RJ. Collective regulation of adolescent misbehavior: Validation results from eighty Chicago neighborhoods. Journal of Adolescent Research 1997; 12:227-244.

Slater S, Nicholson L, Chriqui J, et al. Walkable communities and adolescent weight. American Journal of Preventative Medicine 2013; 44:164-168.

Slater SJ, Ewing R, Powell LM, et al. The association between community physical activity settings and youth physical activity, obesity, and body mass index. Journal of Adolescent Health 2010; 47:496-503.

Taber DR, Chriqui JF, Powell L, Chaloupka FJ. Association between state laws governing school meal nutrition content and student weight status:
Implications for New USDA school meal standards. JAMA Pediatics 2013;167:513-519. doi:10.1001/jamapediatrics.2013.399.

Taber D, Chriqui JF, Chaloupka FJ. Geographic disparities in school district wellness policies targeting youth obesity from 2006-07 to 2008-09. AJPM 2011; 41:407-1.

Worley SE, Story WE. Socioeconomic status and language facility of beginning first graders. Reading Teachers 1967; 20:400-403.

Yen IH, Syme SL. The social environment and health: a discussion of the epidemiologic literature. Annual Review of Public Health 1999; 20:287-308. 